\title{
SOBRE LAS RELACIONES DE VELÁZQUEZ Y DON JUAN DE CÓRDOBA TRAS EL REGRESO DEL SEGUNDO VIAJE A ITALIA
}

\begin{abstract}
Tras el regreso de su segundo viaje a Italia, Diego Velázquez siguió manteniendo una estrecha relación con el agente Juan de Córdoba, quien quedó encargado de concluir el encargo de esculturas hecho por el pintor en Roma. Córdoba compartió a partir de ese momento diversos intereses económicos con Velázquez, ahora en parte desvelados gracias a nuevos documentos.
\end{abstract}

Palabras Clave: Diego Velázquez; Juan de Córdoba; Juan Rubio de Herrera; Agentes; Roma; S. XVII.

\section{ON THE RELATIONSHIP BETWEEN VELÁZQUEZ \& DON JUAN DE CÓRDOBA AFTER THE ARTIST'S RETURN FROM HIS SECOND ITALIAN TRIP}

Following Velazquez's return from his second Italian journey he continued to maintain a close relationship with the agent Juan de Córdoba, who was entrusted with concluding the order for statues made by the painter in Rome. From this time, Córdoba shared various economic interests with Velázquez, now partially revealed thanks to new documents.

Key words: Diego Velázquez; Juan de Córdoba; Juan Rubio de Herrera; Agents; Rome; $17^{\text {th }}$ century.

Los estudios dedicados a esclarecer los pormenores del segundo viaje a Italia de Diego Velázquez han venido a poner de manifiesto el papel primordial que el agente Juan de Córdoba desempeñó en el cumplimiento de una parte fundamental de la misión del maestro. En Roma, Juan de Córdoba trabajó activamente para poder culminar la ambiciosa campaña de encargo de esculturas y vaciados que Velázquez había de llevar a cabo. Los importantes trabajos publicados en los últimos años vienen a confirmar no sólo que el agente participó en el contrato de las esculturas y el seguimiento de su realización durante los meses que el maestro sevillano pasó en Roma, sino también que tras su marcha él fue quien con gran diligencia se encargó de supervisar la conclusión de los trabajos que habían quedado empezados ${ }^{1}$.

Don Juan de Córdoba contaba antes de la segunda estancia de Velázquez en Roma con una amplia experiencia en el servicio al rey de España en la Urbe. Era sobrino del también agente regio Juan Rubio de Herrera, y como él, clérigo y natural de Córdoba. Juan Rubio desde al menos el año 1604 había atendido múltiples asuntos relativos tanto a los intereses de la corona española en Italia como del virrey de Nápoles en la capital pontificia, aunque su llegada a Roma habría que fecharla en realidad antes del año 1583, cuando consta que ya residía en la ciudad ${ }^{2}$. La razón por la que Juan Rubio se asentó definitivamente en Roma no era conocida hasta ahora. En su condición

\footnotetext{
${ }^{1}$ Así lo confirma el magnífico trabajo de PARISI, Antonella, "Per la total perfettione e compimento. La misión de Velázquez y de su agente Juan de Córdoba Herrera en los documentos del Archivo de Estado de Roma", en LuzóN Nogué, José María (dir.), Velázquez. Esculturas para el Alcázar, catálogo de exposición, Madrid, 2007, pp. 83-111. Sobre aquel episodio, ha de verse el pionero trabajo de HARRIs, Enriqueta, "La misión de Velázquez en Italia", Archivo Español de Arte, 39, 1960, pp. 109-136, y también el más reciente de SAlort Pons, Salvador, Velázquez en Italia, Madrid, 2002, pp. 90-146.

2 Véase al respecto Tubino, Francisco María, Pablo de Céspedes, Madrid, 1868, p. 116 y también Rubio LaPAz, Jesús, Pablo de Céspedes y su círculo. Humanismo y contrarreforma en la cultura andaluza del Renacimiento, Granada, 1993, p. 22, nota 10.
} 
de prebendado de la catedral de Córdoba, hubo de presentar por esa fecha un expediente de limpieza de sangre al cabildo catedralicio, a lo que Rubio se resistió. Para conseguir la información necesaria acerca de sus orígenes, la catedral de Córdoba envió a Roma nada menos que a Pablo de Céspedes, con quien Rubio habría mantenido contacto por tanto. El encubrimiento de aquella información se debía a la existencia de judaizantes procesados y condenados por el Santo Oficio entre los antepasados directos de Rubio, tal como la inquisición cordobesa acabaría poniendo de manifiesto en $1620^{3}$. Este hecho, de enorme gravedad en aquel momento, explicaría que el clérigo nunca regresase a su ciudad natal, y también podría justificar que amparase junto a él a su sobrino Juan de Córdoba, protegiéndole así de la acción directa de la inquisición española.

Como agente artístico, la tarea más relevante de Juan Rubio fue la gestión de una parte del conocido encargo de pinturas que en la década de 1630 se realizó en Italia con destino al nuevo real sitio del Buen Retiro ${ }^{4}$. Juan de Córdoba aparece en la documentación por aquellos años junto a su tío, constando que en 1635 firmó como testigo en un acto notarial en el que este último declaraba haber recibido cierta cantidad de dinero del mercader Stefano Pallavicino por orden del conde de Monterrey, quien era entonces virrey en Nápoles ${ }^{5}$.

Tras el fallecimiento de su tío en marzo de $1641^{6}$, Juan de Córdoba se quedó encargado de conducir a buen fin muchas de sus tareas, lo que le llevaría a heredar en cierto sentido el papel que el finado había desempañado durante largos años. La condición de ejecutor testamentario que el sobrino asumió le pondría al tanto de todos los pormenores de los negocios de Juan Rubio, facilitando así la continuación de su labor ${ }^{7}$. De su tío habría heredado también la densa red de contactos sociales en Roma, contándose numerosos artistas entre ellos. No extraña por tanto que la confirmación oficial de su continuidad como agente de los intereses españoles en Roma no tardara en llegar; en 1642, Juan de Córdoba fue nombrado agente del reino de Nápoles por el virrey Medina de las Torres ${ }^{8}$, cargo que le renovaría, poco antes de la llegada de Velázquez a Roma, el conde de Oñate 9

La participación de Juan de Córdoba en el proceso de obtención de copias de esculturas antiguas realizado por Velázquez fue, como la abundante documentación al respecto evidencia, de una importancia capital. El 13 de diciembre de 1649, Velázquez contrata con Giovan Pietro del Duca y Cesare Sebastiani la realización de diversos vaciados de esculturas clásicas en colecciones romanas. El acto se rogó en la casa de Juan de Córdoba ante su presencia, designándosele como la persona ante quienes los artífices habrían de responder del encargo en ausencia del pintor $^{10}$. Unos días más tarde, el 29 de diciembre de 1649, Velázquez acuerda con Girolamo Ferrer

\footnotetext{
3 Sobre este particular, véase Gracia BoIx, Rafael, Colección de documentos para la historia de la inquisición de Córdoba, Córdoba, 1982, pp. 243-247.

${ }^{4}$ Anselmi, Alessandra, "Arte, politica e diplomazia: Tiziano, Correggio, Raffaello, l'investitura del Piombino e notizie su agenti spagnoli a Roma", en Cropper, Elisabeth (dir.), The Diplomacy of Art. Artistic Creation and Politics in Seicento Italy, Bolonia, 2000, pp. 101-120, en especial pp. 113-117.

5 Archivio Storico Capitolino (ASC), Archivio Generale Urbano (AGU), sezione I, notario Jaime Morer, 520, fol. 209rv. Roma, 23 de junio de 1635. Juan de Herrera testifica haber recibido 628 escudos, 16 sueldos y dos dineros de oro del mercader Stefano Pallavicino, residente en Roma, por orden del conde de Monterrey "para que dicho señor otorgante los gaste y emplee en lo que Su Ex.a le ordena como se contiene en el infrascrito orden". Aparecen como testigos Juan de Córdoba y Aníbal Ricci de Viterbo, criado del otorgante.

6 Tormo y Monzó, Elías, Monumentos españoles en Roma, Madrid, 1942, vol. I, p. 79. Murió el 6 de marzo de 1641. Su lápida se conserva en el claustro de Montserrat. Fue colocada por su sobrino y sucesor en los cargos, Juan de Córdoba.

7 ASC, AGU, sezione I, notario Jaime Morer, 524, fol. 83v-85v. Roma, 1 de abril de 1642.

8 Citado por Anselmi, “Arte, politica..." cit., p. 116, nota 69.

9 Biblioteca Apostólica Vaticana (BAV), Ottob. Lat. 3353, I, fol. 66v. Roma, 27 de febrero de 1649: "Il S.r Co: d'Ognate V.Rè di Napoli haveva dechiarato per suo Agente in Roma il Sig.r D. Gio: di Corduba che per spatio di molti anni hà servito la M.tà Catt.ca per Agente di quel Regno".

${ }^{10}$ Pita Andrade, José Manuel (dir.), Corpus Velázqueño, Madrid, 2000, vol. I, pp. 212-214, doc. n. ${ }^{\circ} 244 \mathrm{a}$.
} 
en la casa de Córdoba la realización de tres copias de esculturas de la colección Borghese ${ }^{11}$. El 7 de enero de 1650, el maestro sevillano firmaba con Matteo Bonarelli la fundición de los doce leones de bronce destinados al Salón de los Espejos del Alcázar de Madrid. Una vez más, el acto notarial se realizó "in domo habitatione Illustrissimi domini Ioannis de Cordoba" 2 .

Pero la estancia romana de Velázquez, pese a haber superado los límites temporales que el rey Felipe IV había dispuesto, no fue lo suficientemente larga como para que el pintor pudiera ver concluidas las esculturas que había encargado. Ya el 17 de febrero de 1650, el rey escribía a su embajador en Roma, el VII duque del Infantado, transmitiéndole la orden de que Velázquez regresase a España a finales de mayo o principios de junio de ese mismo año, orden que, como es bien sabido, no fue respetada por el maestro ${ }^{13}$. A Velázquez no sólo le retenían en Roma la misión que Felipe IV le había encomendado y su pasión por el arte, sino también ciertos asuntos de índole personal. El pintor mantuvo en aquella estancia una relación amorosa, probablemente con una viuda llamada Marta, de la que nació el único hijo ilegítimo que se le conoce, el niño llamado Antonio ${ }^{14}$. También Juan de Córdoba asumiría una cierta responsabilidad sobre este niño tras la marcha de Velázquez, como a continuación se recordará.

Según la documentación inédita aquí presentada, el 16 de julio de 1652, Juan de Córdoba requirió los servicios del notario asentado en Roma, Juan Baustista Sola, para resolver un par de cuestiones relativas a sus intereses en España ${ }^{15}$. Por una lado, nombró a su primo Pedro de Herrera y Ahumada como procurador suyo para que cobrara todas las cantidades que se le adeudasen, y particularmente las derivadas de sus beneficios eclesiásticos en España ${ }^{16}$. Por otro, de manera muy significativa, dio poder al mismo Diego Velázquez para que en su nombre pudiera pasar por el Consejo Real o el que correspondiera una citación rotal a favor del otorgante que había sido despachada por el cabildo catedralicio de Córdoba, así como para cualquier otro trámite que tuviera necesidad de realizar ante esos órganos del estado ${ }^{17}$. Parece que la amistad forjada en Roma entre el pintor y el agente hacían que este último viera en Velázquez la persona idónea para representar sus intereses ante la corona, poniendo también de manifiesto la cercanía del pintor a las más altas instancias de la monarquía hispánica.

El poder notarial convertía al mismo Velázquez en agente de Juan de Córdoba en la corte madrileña, curiosa circunstancia que pocos meses más tarde tendría una significativa contraparti-

${ }^{11}$ Ibidem, vol. I, pp. 214-216, doc. n. ${ }^{\circ} 244$ b.

12 Ibid., vol. I, pp. 216-217, doc. n. ${ }^{\circ} 245$.

${ }^{13}$ Ibid., vol. I, p. 218 , doc. n. ${ }^{\circ} 247$.

14 Véase al respecto el revelador artículo de Montagu, Jennifer, "Velázquez Marginalia: his Slave Juan de Pareja and his Illegitimate Son Antonio", The Burlington Magazine, 125, 1983, pp. 683-685.

15 ASC, AGU, sezione I, 726, sin foliar, notario Juan Bautista Sola, 16 de julio de 1652.

${ }^{16}$ Ibidem: "En mi presencia el S.r D. Juan de Cordova clerigo natural de la ciudad de Cordova residente al qual conozco de su libre \& en aquellos \& dixo y otorgó que dava dio y da todo su poder cumplido que de derecho se requiere y es necessario y mexor y mas eficazmente puede y deve valer al S.r Don Pedro de Herrera y Aumada su Primo ausente \& special y expresamente para pedir haver recibir y cobrar judicial y extrajudicialmente qualesquier cantidades de dinero bienes y hazienda que por qualesquier causa razon y ocasion se le deven y devieren y en particular los frutos, rentas, proventos, y emolumentos corridos y por correr madurados y por madurar tanto de todos los Beneficios que el dh S.r otorgante oy en dia goza y posee como de los que por lo venidero tubiere y posseyere (...)".

17 Ibid.: "Dicho dia el mesmo, dixo y otorgó que dava dio y da todo su poder cumplido qual de derecho se requiere y es necesario y mexor y mas efficazmente puede y deve valer al S.r Don Diego de Silva Velazquez Aiuda de Cam. ${ }^{a}$ de su Mag.d (que Dios g.de) y su Aposentador, ausente Special y expresamente para passar por el Consejo Real, o, otro qualquier Consejo de su Mag.d una Citacion Rotal que à favor del dho S.r otorgante ha sido despachada con el Cabildo de Cordova, y otros qualesquier despachos que se puedan ofrecer y otener de los dhos consejos el exequatur, o, exequtoria que fuera necesaria para que los dhos despachos y Citacion Rotal se puedan executar tanto en el dho Cavildo como contra qualquier otra persona y en razon dello hazer todos los autos y diligencias que juzgaren convenir y ser necessarias hasta que con effeto dhos despachos y Citacion Rotal surtan su devido fin y efeto". 
da. Como dio a conocer Jennifer Montagu ${ }^{18}$, el 13 de noviembre de ese año Juan de Córdoba se encargó en Roma de retirar legalmente la tutela del niño Antonio Velázquez a la viuda Marta, quizá su madre o puede que tan sólo su cuidadora, drástico hecho motivado al parecer por no estar recibiendo el pequeño los cuidados oportunos. A partir de ese momento, nada se sabe de la suerte del niño, aunque puede suponerse que Juan de Córdoba seguiría velando por su bienestar.

Es de suponer que el agente tendría puntualmente informado por carta a Velázquez de aquel complejo episodio relacionado con su hijo ilegítimo, al igual que sí consta que seguía comunicándole noticias de índole artística que pudieran ser de su interés. Así se manifiesta en una carta de 23 de diciembre de 1652, en la que Felipe IV le ordenaba a su entonces virrey en Nápoles, el conde de Oñate, comprase unos vasos de pórfido que por entonces estaban a la venta en Roma. El rey había sabido de aquella oportunidad por una epístola enviada por Córdoba a Velázquez en la que incluía los dibujos de los vasos de pórfido que estaban a la venta ${ }^{19}$.

Velázquez tuvo, al parecer, el deseo de volver a Italia en 1657, a lo que el rey Felipe no accedió. Tal vez, el anhelo de ver nuevamente al hijo dejado en Roma le impulsaba al regre$\mathrm{so}^{20}$. El último documento aquí presentado parece confirmar que la relación entre Córdoba y Velázquez no se interrumpió hasta la muerte del maestro sevillano. El agotamiento acumulado durante la organización del encuentro hispano-francés de la Isla de los Faisanes, que como aposentador del rey correspondía a Velázquez, fue el desencadenante de su trágica y prematura muerte en 1660. En Roma, a través de los despachos de la nunciatura, se supo poco tiempo después de su repentino fallecimiento ${ }^{21}$, noticia que circularía con rapidez entre los españoles que residían en la Urbe. Pocos meses después que Juan de Córdoba hubo tenido conocimiento de la muerte de su amigo, el 9 de diciembre de ese mismo año, compareció ante el notario Cristóbal Torrente para dar poder al doctor Juan Pedro Caballón, quien habría de reclamar a los herederos de Velázquez ciertas sumas de dinero que éste le había quedado a deber "por la quenta que entre los dos tenian"22. Por desgracia, el documento no llega a aclarar cuál era esa cuenta común que había entonces de saldarse, puede que a propósito de la manutención del niño Antonio en Roma por parte de Juan de Córdoba, o tal vez derivada de los beneficios que Velázquez podría haber cobrado en nombre del agente. Ni el pintor ni su esposa Juana Pacheco dejaron redactados testamentos en el momento de su muerte, por lo que apenas se disponen de noticias acerca de sus últimas voluntades. Sí consta que don Gaspar de Fuensalida fue designado ante aquella situación como testamentario de Velázquez ${ }^{23}$, siendo él quien seguramente hubo de saldar las cuentas que el finado dejó pendientes con Juan de Córdoba.

DAVID García Cueto Universidad de Granada

\footnotetext{
18 Montagu, J., "Velázquez marginalia...", cit., pp. 684-685.

19 Pita Andrade, J. M., Corpus Velazqueño, cit., I, p. 276.

20 Así lo supone SAlort Pons, S., Velázquez, cit., p. 132.

${ }^{21}$ Ibidem, p. 177 y doc. a140.

22 ASC, AGU, sezione I, 727, sin foliar, notario Cristóbal Torrente, 9 de diciembre de 1660: “A 9 Deziembre 1660. En mi presencia el S.r don Juan de Cordova Clerigo natural de la Ciudad de Cordova estante al presente en esta Corte de Roma al qual conozco de su libre \& en aquello \& dixo y otorgó poder al S.r dotor Juan Pedro Caballon, ausente \& especial y expresamente para pedir haver recibir, y cobrar judicial y extrajudicialm.te de los herederos de Diego de Silva Velázquez y de quien mas fuese necesario qualesquier Cantidad y Cantidades de dinero que pareciere haver quedado deviendo dho Diego de Silva Velázquez à el dho S.r otorgante por la quenta que entre los dos tenían y para este ef.to haçer todas las diligencias necesarias y oportunas y de todo lo que se recibiere y cobrare cartas de pago (...) Fecho en la dimora del dr. Christobal Torrente puesta en la Calle de la Cruz Rion de Campo Março, testigos Girona, y Nono, y Labey".

${ }^{23}$ Pita Andrade, J. M., Corpus Velazqueño, cit., vol. I, p. 484, doc. n. ${ }^{\circ} 437$.
} 